\title{
ANALISIS KUALITAS LAYANAN PENYEDIA DATA DI INDONESIA MENGGUNAKAN METODE SERVQUAL
}

\author{
Lana Sularto*1 \\ ${ }^{1}$ Universitas Gunadarma \\ Email: ${ }^{1}$ lana@staff.gunadarma.ac.id \\ *Penulis Korespondensi
}

(Naskah masuk: 21 November 2019, diterima untuk diterbitkan: 25 Januari 2020)

\begin{abstract}
Abstrak
Tujuan utama penelitian ini untuk melakukan evaluasi kualitas layanan institusi penyedia data untuk berbagai keperluan bisnis maupun penelitian, serta mengukur tingkat kepuasan masyarakat pengguna data di Indonesia dengan menggunakan model SERVQUAL. Kualitas layanan diukur dari perspektif masyarakat pengguna data di wilayah Sumatera Utara, Jawa Timur, Sulawesi Selatan, Kalimantan Selatan, NTB, Maluku dan Papua Barat, sehingga dapat lebih mewakili kebutuhan para pengguna data di wilayah Indonesia. Kuisioner terdiri dari kuisioner persepsi dan harapan dengan menggunakan 5 dimensi SERVQUAL : Reliability, Tangibles, Responsiveness, Empathy dan Assurance. Hasil dari penelitian adalah bahwa kelima dimensi menunjukkan adanya nilai kesenjangan yang negatif, dengan nilai kesenjangan (gap) tertinggi pada dimensi Empathy. Hal tersebut menunjukkan ketidakpuasan pengguna data terhadap layanan penyedia data. Dapat diambil kesimpulan bahwa kualitas layanan penyedia data di Indonesia, belum memenuhi kebutuhan dan keinginan para pengguna data, sehingga perlu dilakukan upaya perbaikan terhadap setiap dimensi yang telah diukur (keandalan, ketersediaan sarana, kesigapan, keempatian dan kepastian) agar dapat meningkatkan kualitas atas layanan penyedia data.
\end{abstract}

Kata kunci: Servqual, Penyedia Data, Kualitas Layanan.

\section{ANALYSIS OF DATA PROVIDER SERVICES QUALITY IN INDONESIA USING SERVQUAL}

\begin{abstract}
The main purpose of this research is to conduct a quality of service of data provider institutions for various business and research purposes as well as measuring the level of satisfaction of the user community in Indonesia using the SERVQUAL model. Measurement of service quality from the point of view of data user communities in the regions of North Sumatra, East Java, South Sulawesi, South Kalimantan, NTB, Maluku and West Papua, to represent user needs of data in Indonesia. The questionnaire consisted of a perception and expectation questionnaire using 5 SERVQUAL dimensions namely Reliability, Tangibles, Responsiveness, Empathy and Assurance. Results showed a negative gap value for all 5 dimensions, where the dimension of empathy has the highest gap. These findings indicate dissatisfaction with data provider services, the conclusion is the quality of data provider services in Indonesia, does not meet the users needs and desires, so it is necessary to make improvements to each dimension that has been measured (eliability, Tangibles, Responsiveness, Empathy and Assurance) in order to improve the quality of data provider services.
\end{abstract}

Keywords: Servqual, Data Provider, Service Quality.

\section{PENDAHULUAN}

Pertumbuhan pengguna internet dan perangkat mobile mendorong sebuah konsep yang disebut dengan big data. Istilah Big Data menggambarkan data yang besar, kompleks dan

kumpulan data independen, yang berpotensi untuk saling berinteraksi (ULARU, et al. 2012). Perkiraan International Data Corp (Reinsel, Gantz and Rydning 2017) bahwa pada tahun 2025, data global akan bertambah menjadi 163 zettabyte (satu triliun gigabyte). Jumlah tersebut sepuluh kali lipat dari 16,1 ZB data yang dihasilkan pada tahun 2016 . Di Indonesia, terjadi peningkatan dari 1 juta terabytes pada tahun 2013 menjadi 5 juta terabytes pada tahun 2017 dan diperkirakan akan meningkat hingga 15 terabytes di tahun 2020 (Agung 2018). Big Data bukan saja berputar pada jumlah data yang dimiliki oleh organisasi, tetapi yang penting lagi adalah bagaimana mengolah data internal dan eksternal. Data dapat diambil dari berbagai sumber lalu 
dianalisa untuk mendapatkan jawaban yang dibutuhkan untuk keperluan bisnis seperti: pengurangan biaya, pengembangan produk baru, pengurangan waktu, optimalisasi penawaran produk serta pengambilan keputusan lainnya.

Namun demikian, penerapan Big Data masih belum populer di Indonesia (Galiartha 2015). Kumpulan data secara independen masih menyebar di masing-masing lembaga penyedia data (data center). Chairman DCI Toto Sugiri menyatakan pertumbuhan data center di Indonesia cenderung lambat karena permasalahan fitur layanan, kepercayaan pengguna dan iklim industri (Aries and Hario 2015). Fitur layanan sangat tergantung dari kebutuhan layanan data yang dibutuhkan masyarakat. Dengan demikian, perlu dievaluasi kualitas layanan yang sudah tersedia saat ini dari perspektif pengguna data.

Banyak model telah digunakan untuk melakukan evaluasi kualitas layanan perusahaan penyedia jasa layanan. Salah satu pendekatan yang populer adalah analisis kesenjangan (Gaps Analysis), analisis tersebut hanya menghitung jarak antara tingkat layanan yang disediakan yang diharapkan pelanggan dan apa yang pada akhirnya pelanggan terima. Pendekatan populer lainnya adalah berdasarkan model Parasuraman, Berry dan Zeithaml (Parasuraman, Berry and Zeithaml 1988), yaitu model SERVQUAL (singkatan dari Service dan Quality) untuk mengukur kualitas layanan. Model ini mengukur bagaimana pelanggan merasakan kualitas layanan perusahaan pada saat pelanggan menerima layanan.

Pengukuran ini dilakukan dengan melakukan perbandingan antara harapan pelanggan tentang bagaimana mereka harus menyediakan layanan dan apa yang akhirnya pelanggan dapatkan. Model SERVQUAL telah dicirikan oleh para penciptanya sebagai skala pengukuran multi-dimensi yang sederhana dan komprehensif yang memiliki hasil dengan tingkat reliabilitas dan validitas yang baik. Para penulis berpendapat bahwa model itu dapat diterapkan pada perusahaan komersial karena harapan dan persepsi pelanggan sangat penting untuk menilai kualitas layanan. Model SERVQUAL dapat digunakan untuk mengukur bagaimana pelanggan merasakan kualitas layanan tersebut.

Penelitian ini bertujuan untuk menentukan tingkat kualitas layanan yang diberikan institusi penyedia data di Indonesia kepada pelanggannya. Untuk keperluan tersebut, masyarakat diwawancarai menggunakan kuesioner yang didasarkan pada model SERVQUAL. Penelitian berfokus pada penyelidikan tentang bagaimana masyarakat mengevaluasi layanan data yang mereka terima. Sampel adalah 95 orang di 7 daerah di Indonesia yaitu : Sumatera Utara (Medan), Jawa Timur (Surabaya), Sulawesi Selatan (Makassar), Kalimantan Selatan (Banjarmasin), NTB (Mataram), Maluku (Ambon) dan Papua Barat (Sorong) yang diberikan kuesioner SERVQUAL.

\section{METODE PENELITIAN}

Untuk mengumpulkan data yang diperlukan, maka disusun kuesioner berdasarkan model SERVQUAL, yang mengacu pada evaluasi kualitas layanan. Kuesioner berisi total enam puluh (60) pertanyaan, dimana lima puluh sembilan (59) pertanyaan tertutup dan satu (1) pertanyaan terbuka. Dengan demikian, dapat diselesaikan dengan mudah dan cepat oleh responden dan sekaligus dapat memberikan semua informasi yang diperlukan untuk melakukan penelitian ini. Instruksi lengkap tersedia untuk mengisi kuesioner dan disampaikan kepada responden oleh orang-orang terlatih untuk menjawab pertanyaan yang mungkin ditanyakan oleh responden.

Dalam perancangan kuesioner ini, struktur yang tepat diupayakan agar kuesioner efektif. Setiap pertanyaan ditujukan untuk tujuan tertentu dan dapat dipahami dan dijawab oleh semua responden. Pertanyaan-pertanyaan disusun dengan jelas, sehingga tidak perlu panduan bagi responden, namun demikian tetap ada pertanyaan filter untuk memastikan bahwa responden menjawab dengan jujur. Pada akhirnya, struktur kuesioner disusun sedemikian rupa agar tidak melelahkan responden.

Lokasi kegiatan survey ini meliputi 7 daerah di Indonesia yaitu : Sumatera Utara (Medan), Jawa Timur (Surabaya), Sulawesi Selatan (Makassar), Kalimantan Selatan (Banjarmasin), NTB (Mataram), Maluku (Ambon) dan Papua Barat (Sorong). Kuesioner diberikan di lokasi pada saat responden berada baik di kantor pemerintah/swasta, di kampus, warnet, sekolah, toko dan tempat lainnya. Responden diberikan instruksi tentang bagiamana cara mengisi kuesioner. Periode penyebaran kuesioner adalah dari awal Juni 2019 hingga akhir Agustus 2019. Kuesioner disebarkan menggunakan metode sampling dan diperoleh 95 kuesioner yang dapat dianggap cukup untuk mencapai random sampel dan ekstrak temuan yang dapat diandalkan. Pertanyaanpertanyaan dari kuesioner dikelompokkan menjadi lima (5) bagian terpisah untuk mempermudah responden menjawab. Bagian pertama dan kedua berisi informasi demografis umum tentang responden agar kami memperoleh pengetahuan tentang profil setiap individu.

Di bagian ketiga, responden diminta untuk menilai layanan penyedia data pada saat ini, dengan skala lima poin dari 'Sangat rendah' (1) hingga 'Sangat penting' (5), hasilnya selanjutnya akan digabung dengan bagian keempat. $\mathrm{Di}$ bagian keempat, responden diminta untuk menilai, pada skala lima poin dari 'Sangat rendah' (1) hingga 'Sangat tinggi' (5), layanan yang diharapkan dari penyedia data.

Akhirnya, bagian kelima adalah pertanyaan terbuka yang dapat diisi oleh responden untuk mengevaluasi layanan penyedia data saat ini, yang selanjutnya akan meningkatkan kualitas layanan yang diberikan kepada mereka di masa depan. 


\section{RELATED WORKS}

Dalam beberapa dekade terakhir, telah banyak penelitian yang memanfaatkan model SERVQUAL. SERVQUAL telah menjadi alat yang dapat dipercaya dan dapat diandalkan untuk pengambilan keputusan sampai hari ini. Studi terbaru yang menggunakan SERVQUAL dalam bidang kesehatan (Riono and Ahmadi 2017); (Umath, Marwah and Soni 2015); (Peprah and Atarah 2014); ( Butt and Run 2010); ( Işik, Tengilimoglu and Akbolat 2011), bidang pendidikan (Stephen, Ahudey and Asamoah 2017), (Đonlagić and Fazlić 2015), (Çerri 2012), (Ulewicz 2014) bidang perbankan (Kakouris and Finos 2016); (Lau, Cheung and Lam 2013); ( Sangeetha and Mahalingam 2011); (Marković, Dorčić and Katušić 2015), dan bidang sistem informasi (Nurhayati 2014); (Marlindawati 2013); (Fathoni 2009); ( Monalisa and Zulkarnaen 2014), seluruhnya telah mengkonfirmasi hal ini. Namun demikian, penelitian mengenai pengukuran kualitas layanan di sektor penyedia data masih terbatas dilakukan oleh penyedia data masingmasing, seperti misalnya Badan Pusat Statistik yang secara rutin setiap tahun mempublikasikan "Analisis Hasil Survei Kebutuhan Data" (BPS 2018) yang merupakan analisis untuk mengukur kebutuhan data statistik serta kepuasan pengguna khusus untuk pengguna data BPS, sehingga belum ada penelitian yang mengukur kepuasan pengguna berbagai macam data (tidak hanya data statistik) untuk berbagai institusi yang menyediakan data yang ada di Indonesia.

Menurut BPS, persentase kepuasan pengguna data terhadap layanan data yang diperoleh dari penyedia data BPS pusat tahun 2018 yang dihitung dengan metode SERVQUAL menunjukkan tingkat kepuasan yang tinggi $(96,96 \%)$ dengan persentase konsumen yang puas terendah terdapat pada kemudahan memperoleh data dari website BPS $(87,69 \%)$. Hal ini menunjukkan bahwa para pengguna data masih merasakan kesulitan untuk memperoleh data yang dibutuhkan di Indonesia, walaupun data dari BPS. Aileen Cater-Steel (Steel and Lepmets 2014) menyimpulkan bahwa walaupun mayoritas responden mengakui pentingnya nilai layanan Teknologi Informasi (TI), namun ternyata sangat sedikit penyedia layanan TI yang benar-benar mengukur nilai layanan TI mereka. Hal ini menunjukkan kurangnya pengukuran tingkat layanan terkait layanan TI. Temuan ini juga mendukung pentingnya mengambil pendekatan sistemik terhadap pengukuran layanan TI. Stabilitas layanan TI akan berdampak pada kepuasan pelanggan, dan kinerja proses mempengaruhi stabilitas layanan TI.

Dalam era globalisasi saat ini, pencarian data yang paling mudah dan cepat adalah pencarian data secara online. Kualitas layanan data secara online menjadi harapan utama para pencari data. Hal ini didukung oleh Faye X. Zhu (Zhu and Wymer 2002) yang menyatakan bahwa layanan yang memiliki basis IT berdampak langsung ke dimensi SERVQUAL dan tidak langsung ke kualitas layanan yang dirasakan pelanggan serta kepuasan pelanggan. Hasil analisis menyatakan bahwa evaluasi oleh pelanggan untuk layanan dengan basis TI dipengaruhi preferensi pelanggan atas layanan tradisional, pengalaman dalam memanfaatkan layanan berbasis IT, dan kebijakan TI yang dirasakan. Temuan-temuan tersebut seharusnya mendorong perusahaan/ organisasi penyedia data agar lebih fokus pada layanan, yang saat ini masih sangat sedikit yang mengukur kualitas layanan mereka dimana pemahaman yang baik mengenai kualitas layanan secara terinci akan memberikan arah dalam upaya perbaikan layanan penyediaan data bagi para pencari data, terutama perbaikan pada layanan berbasis TI. Pada sektor TI, sejumlah kecil upaya penelitian telah ditemukan (Tabel 1).

Tabel 1. Meta Analisis SERVQUAL di sektor Teknologi Informasi

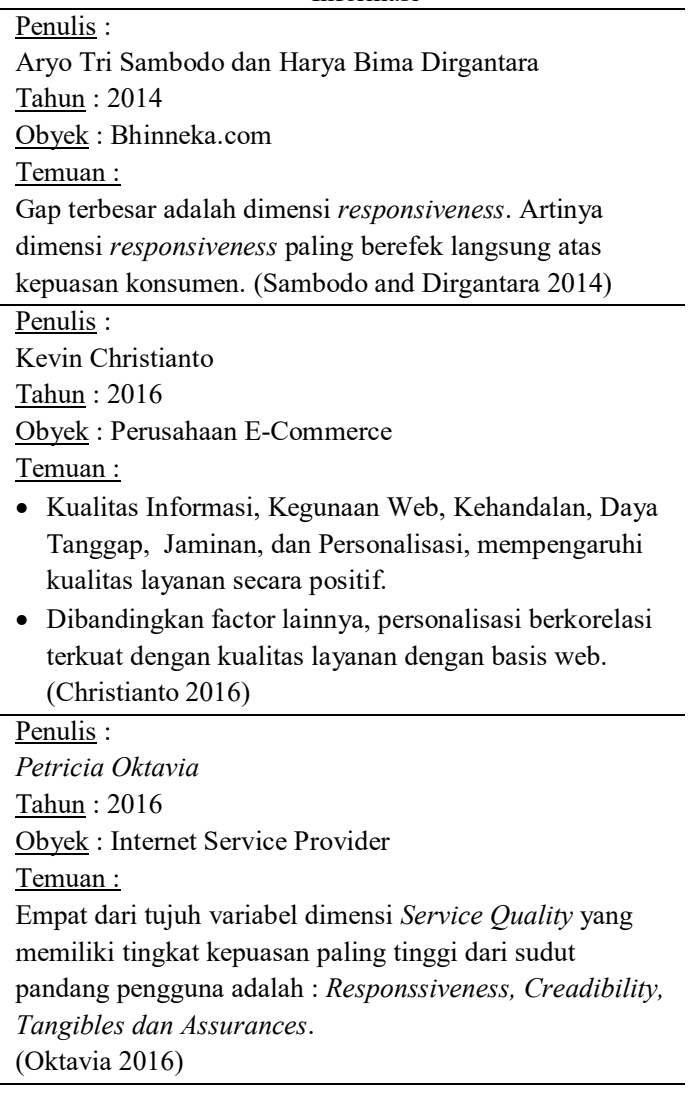

Dari berbagai penelitian kepuasan pengguna data yang sudah dilakukan, masih terbatas dengan obyek penelitian di satu institusi penyedia data saja, belum ada penelitian yang mencoba untuk mengukur kepuasan pengguna data dari berbagai institusi penyedia data baik dari pemerintah maupun swasta. Oleh karena penelitian ini akan memberikan kontribusi berupa gambaran yang lebih komprehensif tentang kepuasan pengguna data di Indonesia, sehingga diharapkan hasilnya akan dapat dimanfaatkan oleh berbagai institusi penyedia data baik swasta maupun pemerintah dalam meningkatkan layanan penyediaan data. 


\section{HASIL DAN PEMBAHASAN}

\subsection{Hasil}

Pengujian validitas instrumen dalam penelitian ini telah dilakukan pada setiap item pertanyaan, yang terdiri atas 60 pertanyaan. Hasil pengujian validitas instrumen untuk setiap item pertanyaan telah valid sesuai dengan kriteria uji validitas yang seluruhnya lebih besar dari 0,3 (Sugiyono, 2011).

Dari hasil bagian pertama dan kedua, profil demografi responden dijelaskan sebagai berikut: mayoritas responden adalah laki-laki (75\%) dan beraktivitas sebagai pegawai baik PNS/Karyawan Swasta dan Pelajar/Mahasiswa $(65,2 \%)$, berusia antara kurang dari 20 tahun sampai 40 tahun (Total $84 \%$ ), berpendidikan SMA ke atas, dan berdomisili di Ambon (21\%), Banjarmasin/Tabalong (20\%), Surabaya (16\%), Medan (15\%), Makasar (13\%), Nusa Tenggara Barat (11\%) dan Sorong (5\%).
Hasil indeks kepuasan pelanggan menunjukkan bahwa kelima dimensi yang diukur memiliki kesenjangan negatif. Dimensi yang memiliki kesenjangan tertinggi adalah dimensi Empathy dengan nilai kesenjangan -2,05 sedangkan untuk kesenjangan terendah pada dimensi Responsiveness dengan nilai -1,55. Dalam dimensi Empathy atribut yang memiliki

kesenjangan tertinggi adalah "upaya memberikan pelayanan yang optimal" sedangkan atribut yang memiliki kesenjangan terendah pada dimensi Responsiveness adalah "kesamaan pelayanan terhadap semua konsumen". Dalam tabel berikut (Tabel 2 dan 3) skor rata-rata harapan, persepsi, dan skor kesenjangan pelanggan disajikan.

\begin{tabular}{lccc}
\multicolumn{4}{c}{ Tabel 2. Indeks Kepuasan Pelanggan Kelima Dimensi } \\
\hline Nimensi & $\begin{array}{c}\text { Nilai Rata- } \\
\text { rata Persepsi }\end{array}$ & $\begin{array}{c}\text { Nilai Rata- } \\
\text { rata } \\
\text { Harapan }\end{array}$ & Kesenjangan \\
\hline Kesigapan (Responsiveness) & 3,24 & 4,79 & $-1,55$ \\
Keandalan (Reliability ) & 3,12 & 5,07 & $-1,95$ \\
Ketersediaan Sarana (Tangible ) & 3,20 & 5,01 & $-1,81$ \\
Kepastian (Assurance) & 3,24 & 4,84 & $-1,60$ \\
Keempatian (Empathy ) & 3,10 & 5,14 & $-2,05$ \\
\hline
\end{tabular}

Tabel 3. Indeks Kepuasan Pelangan Seluruh Atribut dalam Tiap Dimensi

\begin{tabular}{|c|c|c|c|c|}
\hline Dimensi & Atribut & $\begin{array}{c}\text { Nilai Rata- } \\
\text { rata } \\
\text { Persepsi }\end{array}$ & $\begin{array}{c}\text { Nilai } \\
\text { Rata-rata } \\
\text { Harapan } \\
\end{array}$ & $\begin{array}{l}\text { Kesenjang } \\
\text { an }\end{array}$ \\
\hline \multirow{3}{*}{$\begin{array}{l}\text { Kesigapan } \\
\text { (Responsiveness) }\end{array}$} & Seberapa cepat petugas memberikan layanan data ke Konsumen & 3,09 & 4,71 & $-1,61$ \\
\hline & Penguasaan serta kemampuan petugas layanan dalam memberi penjelasan & 3,27 & 4,93 & $-1,65$ \\
\hline & Tingkat kesamaan pelayanan untuk semua konsumen & 3,35 & 4,75 & $-1,40$ \\
\hline \multirow{4}{*}{$\begin{array}{l}\text { Keandalan } \\
\text { (Reliability) }\end{array}$} & $\begin{array}{l}\text { Seberapa lengkap data berdasar waktu dan wilayah dalam bentuk softcopy } \\
\text { atau hardcopy }\end{array}$ & 3,08 & 4,88 & $-1,80$ \\
\hline & Tingkat akurasi data (dapat dipercaya) & 3,14 & 5,26 & $-2,13$ \\
\hline & Tingkat mutakhir data (up to date) & 3,09 & 5,09 & $-2,01$ \\
\hline & Konsep serta definisi yang jelas & 3,17 & 5,04 & $-1,87$ \\
\hline \multirow{6}{*}{$\begin{array}{l}\text { Ketersediaan Sarana } \\
\text { (Tangible) }\end{array}$} & $\begin{array}{l}\text { Seberapa mudah akses ke situs web penyedia data dari berbagai posisi } \\
\text { konsumen }\end{array}$ & 3,27 & 5,05 & $-1,79$ \\
\hline & Lengkapnya data pada situs web penyedia data & 2,92 & 5,11 & $-2,18$ \\
\hline & Mudahnya komunikasi via e-mail pada unit layanan & 3,31 & 5,17 & $-1,86$ \\
\hline & Mudahnya komunikasi via telepon/fax pada unit layanan & 3,39 & 4,87 & $-1,48$ \\
\hline & Mudahnya memperoleh softcopy atas publikasi & 3,34 & 5,07 & $-1,74$ \\
\hline & Mudahnya memperoleh hardcopy atas publikasi & 2,98 & 4,79 & $-1,81$ \\
\hline \multirow{10}{*}{ Kepastian (Assurance) } & Seberapa jelas informasi ketersediaan data/buku/publikasi & 2,87 & 4,83 & $-1,96$ \\
\hline & Tingkat kepercayaan pada independensi data oleh penyedia jasa & 3,40 & 4,97 & $-1,57$ \\
\hline & Tepat waktu dalam penerbitan data/buku/publikasi & 3,26 & 5,07 & $-1,81$ \\
\hline & Tingkat keyakinan atas kualitas data tersedia & 3,23 & 5,21 & $-1,98$ \\
\hline & Tingkat kewajaran biaya pembelian softcopy atas publikasi & 2,66 & 4,81 & $-2,15$ \\
\hline & Tingkat kewajaran biaya pembelian hardcopy atas publikasi & 3,37 & 4,64 & $-1,27$ \\
\hline & Tingkat kewajaran biaya pembelian raw data & 3,53 & 4,76 & $-1,23$ \\
\hline & $\begin{array}{l}\text { Tingkat kesesuaian biaya yang dibayar dengan biaya ditetapkan untuk } \\
\text { membeli softcopy atas publikasi }\end{array}$ & 3,42 & 4,65 & $-1,23$ \\
\hline & $\begin{array}{l}\text { Tingkat kesesuaian biaya yang dibayar dengan biaya ditetapkan untuk } \\
\text { membeli hardcopy atas publikasi }\end{array}$ & 3,32 & 4,75 & $-1,43$ \\
\hline & $\begin{array}{l}\text { Tingkat kesesuaian biaya yang dibayar dengan biaya ditetapkan untuk } \\
\text { membeli raw data }\end{array}$ & 3,36 & 4,75 & $-1,39$ \\
\hline \multirow{3}{*}{$\begin{array}{l}\text { Keempatian } \\
\text { (Empathy) }\end{array}$} & Petugas yang ramah dalam pelayanan & 3,24 & 5,17 & $-1,93$ \\
\hline & Peduli atas keluhan yang muncul & 3,03 & 5,05 & $-2,02$ \\
\hline & Pemberian layanan yang optimal & 3,02 & 5,21 & $-2,19$ \\
\hline
\end{tabular}




\subsection{Pembahasan}

Dari hasil pada tabel "Indeks Kepuasan Pelanggan Kelima Dimensi", terlihat bahwa kesenjangan paling jauh adalah dimensi keempatian (empathy), hal ini menunjukkan bahwa secara umum institusi penyedia data masih belum menunjukkan tingkat keempatian yang diharapkan. Tingkat kesenjangan yang seluruhnya negatif, menunjukkan bahwa pengguna layanan penyedia data masih merasa belum puas dengan layanan yang diberikan sehingga dapat dikatakan bahwa kualitas layanan penyedia data di Indonesia masih perlu untuk ditingkatkan lagi, terutama yang menyangkut dimensi empathy yang memiliki kesenjangan tertinggi. Atribut dalam dimensi empathy yang perlu ditingkatkan berdasarkan urutan kesenjangan adalah "Upaya memberikan pelayanan yang optimal".

Berdasarkan hasil penelitian ini, ditemukan bahwa Empathy, Reliability dan Tangible merupakan dimensi paling penting yang ditunjukkan para pengguna jasa institusi penyedia data. Hal ini terlihat dari nilai rata-rata harapan atas tiga variabel tersebut mempunyai nilai tertinggi (di atas 5). Dengan demikian, responden merasa bahwa 'Responsiveness' dan 'Assurance' dengan nilai rata-rata harapan terendah (di bawah 5), dianggap kurang penting dibandingkan dimensi Empathy, Reliability dan Tangible.

\subsection{Rekomendasi}

Temuan dari penelitian ini dapat membantu perusahaan penyedia data untuk lebih memfokuskan pada dimensi / atribut spesifik yang dianggap penting oleh pelanggan: Empathy, Reliability dan Tangible; dengan demikian, perusahaan penyedia data dapat melakukan tindakan berikut: memberikan tingkat layanan penyediaan data yang optimal, menyediakan data yang dapat diandalkan serta menyediakan berbagai sarana yang lengkap bagi pelanggan agar mudah mendapatkan data yang dibutuhkan.

Akhirnya, agar perusahaan penyedia data dapat menyesuaikan tingkat layanan yang ditawarkan dalam situasi kritis, perusahaan harus menangani setiap persyaratan spesifik dan unik dari pelanggan secara langsung, dan memberikan informasi kepada pelanggan tentang kapan layanan data akan tersedia.

Studi tentang penyedia data yang lebih banyak akan menjadi langkah selanjutnya untuk mengukur layanan yang disediakan oleh penyedia data kepada pelanggannya. Upaya semacam itu dapat membantu mengidentifikasi tidak hanya dimensi yang lebih penting dari layanan yang disediakan tetapi juga mengusulkan tindakan khusus sehingga dapat membantu organisasi penyedia data untuk meningkatkan layanan yang mereka berikan kepada pelanggan mereka dengan berfokus pada dimensidimensi ini.

\section{KESIMPULAN}

Kualitas layanan penyedia data di Indonesia dapat dikatakan belum cukup baik karena berdasarkan indeks kepuasaan pelanggan dari lima dimensi ServQual menunjukkan kesenjangan yang negatif. Hal ini mengindikasikan bahwa penguna layanan penyedia data di Indonesia belum terpuaskan dengan layanan yang diberikan. Dimensi yang memiliki kesenjangan tertinggi adalah dimensi Empathy. Penelitian ini memiliki sejumlah keterbatasan, pertama, fakta bahwa sampel dalam penelitian ini hanya terbatas di 7 daerah di Indonesia yang mungkin tidak memberikan pandangan holistik mengenai persepsi pelanggan. Selain itu, model SERVQUAL memiliki keterbatasan, misalnya SERVQUAL berorientasi pada proses: ia berfokus pada proses penyampaian layanan, bukan pada hasil dari pertemuan layanan, dan juga fakta bahwa lima dimensi SERVQUAL tidak bersifat universal. Dengan demikian, disarankan agar dilakukan perluasan sampel penelitian ke wilayah yang lebih luas, serta penambahan metode penelitian untuk mengatasi kelemahan SERVQUAL

\section{DAFTAR PUSTAKA}

BUTT, MOHSIN MUHAMMAD, \& ERNEST CYRIL DE RUN. 2010. "Private healthcare quality: applying a SERVQUAL model." International Journal of Health Care Quality Assurance 658.

IŞIK, OĞUZ, DILAVER TENGILIMOGLU，\& MAHMUT Akbolat. 2011. "Measuring Health Care Quality with the SERVQUAL Method: A Comparison in Public and Private Hospitals." HealthMED Journal of Society for development in new net environment in B\&H 1921.

MONALISA, SITI, \& ARROFIK ZULKARNAEN. 2014. "Evaluasi Kualitas Layanan Sistem Informasi Manajemen Kepegawaian (SIMPEG) Menggunakan Metode Servqual (Studi Kasus : Kemenag Kota Pekanbaru)." Jurnal Sains, Teknologi dan Industri 282.

SANGEETHA, JAYA, AND S MAHALINGAM. 2011. "Service quality models in banking: A review." International Journal of Islamic and Middle Eastern Finance and Management 83.

AGUNG. 2018. Kebutuhan Data Semakin Bertambah, Bervariasi dan Cepat Mengalir. September 24. Accessed November 11, 2018. https://ugm.ac.id/id/berita/17091-

kebutuhan.data.semakin.bertambah.bervariasi.da n.cepat.mengalir

ARIES, \& HARIO. 2015. Kementerian Komunikasi dan Informatika Republik Indonesia. December 22. Accessed November 10, 2018. https://kominfo.go.id/content/detail/6536/kominf o-antisipasi-kebutuhan-layanan-datacenter/0/berita_satker. 
BPS. 2018. Analisis Hasil Survei Kebutuhan Data 2018. Jakarta: Badan Pusat Statistik.

ÇERRI, SHPËTIM. 2012. "Assessing The Quality Of Higher Education Services Using A Modified Servqual Scale." Annales Universitatis Apulensis Series Oeconomica 664.

CHRISTIANTO, KEVIN . 2016. "Hubungan Dimensi Service Quality Dengan Kualitas Layanan E-Commerce Dari Sudut Pandang Konsumen Online." Jurnal Teknologi Informasi, Program Studi Teknik Informatika Dan Sistem Informasi, Universitas Bunda Mulia 15.

ĐONLAGIĆ, SABINA, \& SAMIRA FAZLIĆ. 2015. "Quality Assesment in Higher Education using The SERVQUAL Model." Management 20: 39.

FATHONI. 2009. "Analisis Kualitas Layanan Sistem Informasi menggunakan Metode SERVQUAL." Konferensi Nasional Sistem dan Informatika 2009. Bali: STIKOM BALI. 1.

GALIARTHA, GILANG. 2015. Antaranews. Januari 30. Accessed November 11, 2018. https://www.antaranews.com/berita/477310/tigabidang-usaha-pengguna-utama-big-data-diindonesia.

KAKOURIS, ANDREAS P, \& PANAGIOTIS K FINOS. 2016. "Applying Servqual To The Banking Industry." Journal ofEconomics and Business 57.

LAU, MEI MEI, RONNIE CHEUNG, \& ARIS Y. C. LAM. 2013. "Measuring Service Quality in the Banking Industry: A Hong Kong Based Study." Contemporary Management Research 263.

MARKOVIĆ, SUZANA , JELENA DORČIĆ, \& GORAN KATUŠIĆ. 2015. "Service Quality Measurement in Croatian Banking Sector: Application of SERVQUAL Model." Managemetn International Conference (MIC) 2015. Portoroz, Slovenia: Researchgate. 209.

MARLINDAWATI. 2013. "Analisis Kualitas Layanan Sistem Informasi Menggunakan Servqual Method." Seminar Nasional Aplikasi Teknologi Informasi (SNATI) 2013. Yogyakarta: Universitas Islam Indonesia. C-47.

NURHAYATI, LENI . 2014. "Analisis Kualitas Layanan Sistem Informasi Akadmeik (Studi Kasus STMIK Sumedang)." Jurnal STMIK Sumedang STMIK Sumedang.

OKTAVIA, PETRICIA . 2016. "Penerapan Metode Servqual dan Metode Eucs dalam Mengevaluasi Kepuasan Pelanggan dan Kualitas Layanan Teknologi Informasi Pengguna Jasa Internet Service Provider (Studi Kasus pada PT. Platinum Citra Indonesia, Tangerang)." Jurnal Informatika Universitas Pamulang 69.

PARASURAMAN, A PARSU, LEONARD L BERRY, \& VALARIE A ZEITHAML. 1988. "SERVQUAL A Multiple-item Scale for Measuring Consumer Perceptions of Service Quality." Journal of Retailing 12.
PEPRAH, AUGUSTINE AWUAH , \& BEDE AKORIGE ATARAH. 2014. "Assessing Patient's Satisfaction Using SERVQUAL Model: A Case of Sunyani Regional." International Journal of Business and Social Research (IJBSR) 133.

REINSEL, DAVID, JOHN GANTZ, \& JOHN RYDNING. 2017. Data Age 2025: The Evolution of Data to Life-Critical, Don't Focus on Big Data; Focus on the Data That's Big. White Paper, Framingham, Massachusetts: International Data Corporation (IDC).

RIONO, \& AHMADI. 2017. "Analysis of Healthcare Services Quality Using Servqual - Fuzzy Method." International Journal of Economics \& Management Sciences. 485.

SAMBODO, ARYO TRI, \& HARYA BIMA DIRGANTARA. 2014. "Analisis Kepuasan Konsumen dengan SERVQUAL Studi Kasus : Media Sosial bhinneka.com." Seminar Nasional Sistem Informasi Indonesia (SESINDO). Surabaya: Jurusan Sistem Informasi, Fakultas Teknologi Informasi, Institut Teknologi Sepuluh Nopember (ITS). 37.

STEEL, AILEEN CATER, \& MARION LEPMETS. 2014. "Measuring IT service quality: evaluation of IT service quality measurement framework in industry." Journal of Service Science Research 125.

STEPHEN, BANAHENE, ERIC AHUDEY, \& ABIGAIL ASAMOAH. 2017. "Analysis of SERVQUAL Application to Service Quality Measurement and Its Impact on Loyalty in Ghanaian Private Universities." Journal of Management and Strategy 8 (4): 18.

SUGIYONO. 2011. "Metode Penelitian Kuantitatif Kualitatif dan R\&D". (cetakan ke-14). Bandung: Alfabeta.

ULARU, ELENA GEANINA, FLORINA CAMELIA PUICAN, ANCA APOSTU, \& MANOLE VELICANU. 2012. "Perspectives on Big Data and Big Data Analytics." Database Systems Journal 3.

ULEWICZ, R. 2014. "Application Of Servqual Method For Evaluation Of Quality Of Educational Services At The University Of Higher Education." Polish Journal Of Management Studies 254.

UMATH, BHUPESH, AMIT KUMAR MARWAH, \& MANISH SONI. 2015. "Measurement of Service Quality in Health Care Industry using Servqual Model: A Case of Select Hospitals." International Journal of Management and Social Sciences Research (IJMSSR) 52.

ZHU, FAYE X, \& WALTER WYMER. 2002. "ITbased services and service quality in consumer banking." International Journal of Service Industry Management 69. 